\title{
1 Effect of Pulsed Light Treatment on the Functional Properties of Casein Films
}

\author{
Mila Wihodo, Carmen I. Moraru*
}

5 Abstract. In this study, the effect of Pulsed Light (PL) treatment as a cross-linking method on

6 the properties of casein films was evaluated. Casein films were prepared from micellar casein

7 concentrate, with $5 \mathrm{~g} / 100 \mathrm{~g}$ glycerol added as a plasticizer. The UV-curable resins PEG (200)

8 diacrylate and PEG (400) diacrylate were added as photo-initiators. Films were prepared by

9 casting and equilibrated under a range of relative humidity $(\% \mathrm{RH})$, then treated with Pulsed

10 Light (PL), with up to 15 pulses of light on each side, at a fluence of $1.57 \mathrm{~J} / \mathrm{cm}^{2}$ per pulse. The

11 microstructure, mechanical and water barrier properties, water sorption and hydrophobicity of

12 the films were evaluated. PL treatment of casein films with up to 12 pulses increased the films'

13 smoothness and homogeneity, while higher levels of treatment caused structural defects.

14 Mechanical strength and elongation of some of the films, particularly those with added PEG

15 (400) diacrylate, were significantly increased by PL, but no improvement of their water vapor

16 permeability was observed. The incorporation of PEG (200) diacrylate resulted in highly porous

17 film microstructures, and interesting photo-patterning effects observed at high PL doses. These

18 results indicate the potential of PL for creating protein films with unique characteristics and

19 functionality.

21 Keywords: casein films; Pulsed Light; PEG; cross-linking; photo-polymerization

\footnotetext{
Corresponding author. Tel: + 16072558121

Email address: cim24@cornell.edu (C.I. Moraru)
} 


\section{Introduction}

Biopolymer films are often considered as an alternative to plastic films. Protein films in

24 particular have attracted significant attention of researchers and industry in recent years.

25 Biopolymers in general and protein films in particular have great potential for use as food

26 packaging, as well as edible films and coatings (Peterson and others, 1999; Wihodo and Moraru,

27 2013). Edible films can for instance be placed within a dual texture food, such as pizza, to

28 prevent moisture migration and maintain the texture of each of the layers (Kester and Fennema,

29 1989). A significant drawback of protein films is that they have a higher water vapor

30 permeability compared to most synthetic polymers (Krochta, 1992; McHugh and Krochta, 1994).

31 Furthermore, protein films are generally weaker and have lower elongation than synthetic films

32 (Hernandez-Izquierdo and Krochta, 2008). Various methods to enhance the physical properties

33 of protein films have been suggested (Wihodo and Moraru, 2013).

Milk proteins, including casein and whey proteins are considered exceptional candidates

35 for biodegradable films (McHugh and Krochta, 1994). Many studies reported on methods to

36 improve the functional properties of films made from casein and casein derivatives, including:

$37 \mathrm{pH}$ alteration (Avena-Bustillos and Krochta, 1993), lipid incorporation (Chick and Hernandez,

38 2002; Sohail et al., 2006; Fabra et al., 2009) and combination with polysaccharides (Fabra et al.,

39 2008, Pereda et al., 2008). A newer method used to improve the functional properties of protein

40 films is photo-induced polymerization, which uses light to initiate and propagate a

41 polymerization reaction to form a cross-linked polymer structure (Baroli, 2006). For photo-

42 polymerization to occur, the backbone of the monomer used needs a photo-polymerizable

43 residue at one or both ends of the molecule (Baroli, 2006). The addition of photoinitiators is

44 generally necessary to initiate the polymerization reaction. The first step in a photo-initiated 
45 polymerization is initiation, which begins when an initiator molecule decomposes into free

46 radicals in the presence of monomers. The instability of carbon-carbon double bonds in the

47 monomer makes them susceptible to reaction with the unpaired electrons in the radical, which

48 "grabs" one of the electrons from the double bond in the monomer. This leaves an unpaired

49 electron at the end of the monomer chain, which thus becomes a free radical (Ifkovits and

50 Burdick, 2007). The next stage is propagation, when the electron transfer and motion of the free

51 radical down the chain take place. The process ends with the termination reaction, which occurs

52 when the growing polymer chain joins with another free radical (Ifkovits and Burdick, 2007).

53 Photo-polymerization has typically been achieved by continuous UV (Genadios et al.,

54 1998; Rhim et al., 1999; Vaz et al., 2003). Rhim et al. (1999) reported that an UV dose of 51.8

$55 \mathrm{~J} / \mathrm{m}^{2}$ increased the tensile strength of sodium caseinate films by $2.5 \%$, of egg albumin films by

$5670.6 \%$, of corn zein film by $20 \%$, and of wheat gluten films by $66.7 \%$. In another report, the

57 same UV dose $\left(51.8 \mathrm{~J} / \mathrm{m}^{2}\right)$ increased the tensile strength of SPI films by $41.9 \%$ (Gennadios et al., 58 1998).

Pulsed Light (PL) technology is another type of light treatment, consisting of intense and

60 short duration pulses of broad spectrum light, in the wavelength range $200-1,100 \mathrm{~nm}$, produced

61 using gas discharge lamps (Dunn et al., 1991). The use of PL for microbial inactivation has been

62 reported quite extensively (Uesugi et al., 2007; Woodling and Moraru, 2007; Uesugi and

63 Moraru, 2009; Krishnamurthy et al., 2010; Cheigh et al., 2012), but the potential of this

64 technology for photo-polymerization applications has not yet been explored.

65 Research suggests that an efficient photo-polymerization reaction occurs when the

66 absorption spectrum of the treated material matches the emission spectrum of the light source

67 (Scherzer et al., 2005) and that the rate of the initiation reaction is proportional to the intensity of 
68 the light source (Ifkovits and Burdick, 2007). The broad spectrum of light and the high light

69 intensity suggest that PL has a great potential to initiate efficient photo-polymerization. PL also

70 offers the advantage of much shorter treatment duration as compared to continuous UV. The

71 objective of this work was to explore the effectiveness of PL as a photo-polymerization

72 technique for improving the structural and mechanical properties of casein films.

74 2. Materials and Methods

\section{$75 \quad$ 2.1. Film Preparation}

Micellar casein (MCC) powder was obtained from the American Casein Company

77 (Burlington, NJ). Protein dispersions of $10 \mathrm{~g} / 100 \mathrm{~mL}$ concentration were prepared by dispersing

78 MCC powder in ultrafiltered water at $22 \pm 2{ }^{\circ} \mathrm{C}$. The protein dispersion was first stirred under

79 moderate agitation on a magnetic stirring plate (Thermix® Stirring Hot Plate, Fisher Scientific,

80 Pittsburgh, PA) for 20 min, followed by intense agitation (21,500 RPM) for 5 min using an

81 UltraTurrax mixer (IKA Works Inc., Wilmington, NC). To ensure complete hydration, the

82 mixture was then heated in glass bottles at $40^{\circ} \mathrm{C}$ for $15 \mathrm{~min}$ in a water bath, then cooled to $20^{\circ} \mathrm{C}$.

83 After heating, $5 \mathrm{~g} / 100 \mathrm{~g}$ glycerol (Mallinckrodt Baker, Inc., Phillipsburgh, NJ) was added to the

84 protein mixture as a plasticizer. To further enhance the functional properties of the protein films,

$855 \mathrm{~g} / 100 \mathrm{~g}$ UV-curable resins were added to some of the samples. The resins used in this study

86 were polyethylene glycol (PEG) (200) diacrylate (DA) and PEG (400) DA (Sartomer Company,

87 Inc., Exton, PA), both of which have GRAS status (21 CFR 175). An evaluation of light

88 absorption by casein and the resins was carried out, to ensure that all components of the films

89 absorb light in the UV range. Casein absorbs light from $200 \mathrm{~nm}$ to $1100 \mathrm{~nm}$, which coincides 
90 with the spectral range of the PL source, while PEG-200 and PEG-400 show strong absorption

91 peaks between 200-300 nm (Fig. 1).

92 The protein dispersion with added glycerol and resins was poured onto polystyrene

93 square Petri plates (Fisher Scientific, Pittsburgh, PA). A volume of $10 \mathrm{ml}$ per plate was used, to

94 maintain a constant thickness of the final films. The plates were placed on a leveled bench top

95 and allowed to air dry under a laminar hood for $48 \mathrm{~h}$ at $22 \pm 2{ }^{\circ} \mathrm{C}$ and $35 \%$ relative humidity

$96(\% \mathrm{RH})$. The dried films were then peeled off from the plates, then cut in rectangular strips of 1

$97 \mathrm{~cm} \times 3 \mathrm{~cm}$. Film thickness was measured using a hand held caliper (Traceable Digital Caliper,

98 Fisher Scientific, Pittsburgh, PA,), at 3 random positions of the film.

99

100

\subsection{Pulsed Light Treatment}

101

PL treatments were performed using a RS-3000C SteriPulse System (Xenon Corporation,

102 Woburn, MA). Each film strip was centered individually on an adjustable stainless steel shelf in 103 the PL unit, at $3.2 \mathrm{~cm}$ beneath the Xenon lamp, and treated with 0 (control), 9, 12, and 15 pulses

104 of light on each side (the films were treated on one side, then flipped and treated on the other

105 side). The PL dose (fluence) was measured using a pyroelectric head with a Nova II display

106 (Ophir Optronics Inc., Wilminton MA) and expressed in $\mathrm{J} / \mathrm{cm}^{2}$. Fluence measurements were

107 performed in triplicate. The measured fluence at the sample treatment location was $1.57 \mathrm{~J} / \mathrm{cm}^{2}$ 108 per pulse.

109

$110 \quad$ 2.3. Film Conditioning

111 After PL treatment, the film strips were stored in glass desiccators over supersaturated 112 solutions of $\mathrm{LiCl}, \mathrm{MgCl}_{2}, \mathrm{Mg}\left(\mathrm{NO}_{3}\right)_{2}, \mathrm{NaCl}$ and $\mathrm{KCl}$, which resulted in different \% $\mathrm{RH}$ values in 
113 the headspace. Water was used to create a headspace of \%RH close to $100 \%$. Films were allowed

114 to equilibrate at $22 \pm 2{ }^{\circ} \mathrm{C}$ for 3-4 days. After conditioning, the water activity $\left(\mathrm{a}_{\mathrm{w}}\right)$ of the films

115 was measured at $25^{\circ} \mathrm{C}$ using an AquaLab Series 3 hygrometer (Decagon Devices, Inc., Pullman,

116 WA).

118 2.4. Evaluation of Film Microstructure

119 The microstructural features of the films were observed using scanning electron

120 microscopy (SEM). Film specimens were first dehydrated and then sputter-coated with Au using

121 a Denton Vacuum Desk II Cold Sputter Etch Unit (Denton Vacuum, Moorestown, NJ). The

122 sputter-coated samples were viewed with a Leica Stereoscan 440 SEM (Leica Cambridge Ltd.,

123 Cambridge, England), at a voltage of $10 \mathrm{kV}$ and a maximum magnification of $1500 \mathrm{X}$, at the

124 Cornell Center for Materials Research (Ithaca, NY).

125

\subsection{Mechanical Properties of the Films}

Mechanical properties were measured using a TA-XT2 texture analyzer (Stable Micro

128 Systems, Texture Technologies Corp., Scarsdale, NY). The experiments were performed at

129 approximately $40 \% \mathrm{RH}$ and $22 \pm 2{ }^{\circ} \mathrm{C}$. X. Each specimen was tested immediately after being

130 taken out of the desiccator, to minimize dehydration.

131 Film tensile strength and \% elongation at break were evaluated according to ASTM

132 Standard D 882-02 (ASTM 2003). The initial grip separation was $30 \mathrm{~mm}$, and the test crosshead

133 speed was $0.1 \mathrm{~mm} / \mathrm{s}$. A minimum of 8 samples were measured for each film type and two

134 replications were conducted. Tensile strength (MPa) was calculated as the peak force (N) divided 
135 by initial cross-sectional area $\left(\mathrm{m}^{2}\right)$. Film elongation was reported in percent of length increase 136 divided by the original film length.

137 The study was replicated twice. Due to slight differences in \% RH between the two 138 replicates, the results of each replicate were reported separately.

\section{2.6. Water Vapor Permeability (WVP)}

141 Glass jars with metal lids and metal rings lined with neoprene-band seal to ensure air

142 tightness (Ball Corporation, Muncie, IN) were used to measure water vapor transmission rate 143 (WVTR) of the films. The dimension of a jar without the lid was $7.37 \mathrm{~cm} \times 7.37 \mathrm{~cm} \times 5.84 \mathrm{~cm}$ 144 (2.9 in $\times 2.9$ in $\times 2.3$ in). To mount the film strip, a rectangular window of $1 \mathrm{~cm} \times 3 \mathrm{~cm}$ was cut 145 out from the center of the metal lid and the film specimen was taped to the lid. The shape and 146 size of the film strips were chosen to match the profile of the PL lamp and ensure uniformity of 147 the PL treatment.

148 Each glass jar was filled with deionized water to expose the underside of the film to $149100 \%$ RH. The whole assembly was placed in an acrylonitrile-styrene desiccator cabinet (Fisher 150 Scientific, Pittsburgh, PA). The temperature in the desiccator cabinets was maintained at $22 \pm 2$ $151{ }^{\circ} \mathrm{C}$ by placing them in a temperature controlled chamber. Values of $\% \mathrm{RH}$ of $11 \%, 32 \%, 53 \%$, $15275 \%$, and $84 \%$ were achieved using supersaturated solutions of $\mathrm{LiCl}, \mathrm{MgCl}_{2}, \mathrm{Mg}\left(\mathrm{NO}_{3}\right)_{2}, \mathrm{NaCl}$, 153 and $\mathrm{KCl}$, respectively. Equilibrium was reached within $3 \mathrm{~h}$, at which time the assembly was 154 weighed again. Four more data points were collected at $3 \mathrm{~h}$ intervals, over a $12 \mathrm{~h}$ period.

155 To avoid the existence of a stagnant air layer above the film (Gennadios et al., 1994), 156 small hand held fans were placed inside the desiccator cabinets to provide forced convection 157 conditions and constant air flow. The \% RH and temperature in the desiccators were monitored 
158 with a digital thermometer-hygrometer (Fisher Scientific, Pittsburgh, PA). The height of the

159 stagnant air gaps inside the jars were measured before and after the experiments using a

160 handheld caliper (Fisher Scientific, Pittsburgh, PA). The mean of initial and final stagnant air

161 gap height was used for WVP calculation. The stagnant air gap height of all samples was always

162 less than $14 \mathrm{~mm}$ to ensure accurate WVP determination (McHugh et al., 1993).

163 Water vapor permeability (WVP) was calculated according to the method of Gennadios

164 et al. (1994). First, a linear regression analysis of weight loss as a function of time was

165 performed to ensure that steady state slopes were achieved. The regression coefficients (RÇ)

166 were greater than 0.970 for all samples. WVTR was calculated as the slope divided by the area

167 of the film exposed in the test jar $\left(3 \mathrm{~cm}^{2}\right)$ :

$$
W V T R=\frac{\text { Slope }}{\text { Area }}
$$

To account for the diffusion of water vapors through the stagnant air layer inside the test

171 jar, the corrected partial pressure of water vapor at the underside of the film $\left(p_{2}\right)$ was calculated

172 as:

173

$$
W V T R=\frac{P^{*} D^{*} \operatorname{Ln} \frac{P-p_{2}}{P-p_{1}}}{R^{*} T^{*} \Delta z} \quad\left(\mathrm{~kg} / \mathrm{m}^{2} \mathrm{~s}\right)
$$

174

176 calculate water vapor permeance:

$$
\text { Permeance }=\frac{\text { WVTR }}{p_{2}-p_{3}} \quad\left(\mathrm{~kg} / \mathrm{m}^{2} \mathrm{sPa}\right)
$$

178

179 The water vapor permeability (WVP) was finally determined by multiplying the 180 corrected permeance and film thickness: 


$$
\text { WVP }=\text { Permeance } * \text { Film Thickness } \quad\left(\mathrm{g} \mathrm{m} / \mathrm{m}^{2} \mathrm{sPa}\right)
$$

182 where,

illustrated schematically in Fig. 2. Three samples of each film type were measured in each

194 replicate and the study was replicated twice.

195

\subsection{Moisture Sorption Isotherms}

Water activity $\left(\mathrm{a}_{\mathrm{w}}\right)$ of the films was measured as described above. To determine the

198 moisture content, the equilibrated films were quickly transferred to a 55-mm diameter aluminum

199 dish (Fisher Scientific, Pittsburgh, PA) and weighed using an analytical balance (Denver

200 Instrument, Denver, CO). The samples were then dried in an Isotemp Standard Lab Oven

201 (Fisher Scientific, Pittsburgh, PA) at $103 \pm 2{ }^{\circ} \mathrm{C}$ for $24 \mathrm{~h}$, re-weighed and their moisture content

202 calculated based on the moisture loss during drying. Three replicate measurements were 
203 conducted. Moisture sorption isotherms were built by plotting the measured moisture content of

204 the films vs. $\mathrm{a}_{\mathrm{w}}$.

205 The GAB (Guggenheim-Anderson-de Boer) model was used to fit the sorption isotherm

206 data. Monolayer values for moisture were calculated according to Iglesias and Chirife (1982):

207

208

$$
M=\frac{m_{0} C_{G} k a_{w}}{\left(1-k a_{w}\right)\left(1-k a_{w}+C_{G} k a_{w}\right)}
$$

209 where $M$ is the equilibrium moisture content at a water activity $a_{w}, m_{0}$ is the monolayer value, $C_{G}$

210 is the Guggenheim constant, and $k$ is the constant correcting properties of the multilayer

211 molecules relative to the bulk liquid.

212

The GAB constants were determined by re-writing Equation 5 as Equation 6, followed by

213 plotting $a_{w} / M$ as a function of $\mathrm{a}_{\mathrm{w}}$.

214

215

$$
\frac{a_{W}}{M}=\frac{k}{m_{0}}\left(\frac{1}{C_{G}}-1\right) \cdot a_{W}^{2}+\frac{1}{m_{0}}\left(1-\frac{2}{C_{G}}\right) \cdot a_{W}+\frac{1}{k \cdot m_{0} \cdot C_{G}}
$$

216 The constants of the second degree polynomial obtained by fitting the data were then used to

217 calculate $C_{G}$ and $k$.

218

219

\subsection{Water Contact Angle Measurements}

The water contact angles of the films were measured using a Tantec CAM-Plus

221 goniometer (Schaumburg, IL), by delivering a droplet of deionized water to the surface of the

222 film and viewing it through the eyepiece of the goniometer (Goddard and Hotchkiss, 2007). A

223 minimum of 10 measurements were performed for each film type. The average angle values

224 were used as a measure of surface hydrophobicity.

225 


\subsection{Statistical Analysis}

Two-way ANOVA tests with an interaction effect were performed on the values of

228 tensile strength, \% elongation, WVP and water contact angles to determine any significant

229 differences in the properties of casein films due to PL treatment and relative humidity conditions.

230 Any differences between means were compared based on the Tukey-Kramer HSD test, with

231 significance defined at $\mathrm{p} \leq 0.05$. All statistical analyses were performed using JMP version 7.0

232 (SAS Institute Inc., Cary, NC).

\section{3. Results and Discussion}

\subsection{Microstructural Features of the Pulsed Light Treated Casein Films}

Electron micrographs of the casein films revealed a visible increase in surface

237 smoothness and homogeneity after PL treatment with up to 12 pulses $\left(18.8 \mathrm{~J} / \mathrm{cm}^{2}\right)$ per side, as

238 shown in Fig. 3 (top row). At 15 pulses $\left(23.5 \mathrm{~J} / \mathrm{cm}^{2}\right)$, PL treatment caused some cracking on the

239 film surface. Irradiating proteins in solid state could lead to cross-linking or molecular

240 degradation, depending on the nature of the protein and irradiation dosage (Rhim et al., 1999).

241 The presence of the fine cracks in the films treated with high doses of PL in this study suggests

242 that the 15 pulses treatment may be in the range where light-induced degradation of the casein

243 matrix starts to occur. This is very important to note, since such structural defects will affect the

244 films' mechanical and barrier properties.

245 The incorporation of PEG (400) DA in casein resulted in films that closely resembled the

246 appearance of casein films, with occasional micrometer sized circular pores in their structure.

247 The addition of PEG (200) DA to casein resulted in a "sponge-like" structure of the films, with

248 fairly large pores, in the range of tens of $\mu \mathrm{m}$ (Fig. 3, bottom row). PL did not cause noticeable 
changes to the microstructure of casein films with PEG (400) DA. For the casein films with PEG

250 (200) DA, PL with 15 pulses drastically reduced the size of the surface pores. The observed

251 'closing' of the pores bears a resemblance with the UV patterning reported by Yu et al. (2008)

252 and Choi et al. (2008), and is an indication of cross-linking within the film's matrix due to PL.

\subsection{Effect of Resin Addition and PL on Surface Hydrophobicity of Casein Films}

Wetting by water is always an issue of concern for any packaging material, and

256 particularly for food packaging. The water contact angles (WCA) for the films produced in this

257 work are shown in Fig. 4. The casein films and films with PEG (200) DA had WCA values of

258 about $50^{\circ}$, which indicates a moderately hydrophilic character. For the films with PEG (400)

259 DA, an average WCA of $11.5^{\circ}$ was obtained, which indicates a fully wetting behavior. PL

260 treatment induced some changes in WCA of the films. WCA of casein films with PEG (400) DA

261 increased significantly after PL with 15 pulses as compared to the untreated films $(\mathrm{p} \leq 0.05)$.

262 WCA of films treated with 15 pulses were significantly lower compared to the other treatment

263 levels. This increase in the wetting characteristics of the films after PL treatment is consistent

264 with previous reports about the effect of UV on the wetting properties of materials (Zubkov et

265 al., 2005). Overall, the high wettability of the casein films with added resins suggests that they

266 may not be suitable for applications where contact with water is a concern.

267

\subsection{Effect of PL on Water Sorption Properties of Casein Films}

For all types of films generated in this study, J -shaped isotherms were obtained (Fig. 5),

270 which is typical for most protein-based matrices (Jangchud and Chinnan, 1999; Cho and Rhee,

271 2002; Foster et al., 2005). PL treatment did not have any significant effect on the moisture 
272 sorption properties of the casein films. For the casein films with added resins, a slight decrease

273 in moisture sorption capacity was observed for the PL treated films at high water activity levels.

274 The moisture isotherms were fitted using the GAB model, and the constants $C_{G}, m_{0}$ and $k$

275 were calculated (Table 1). The high $R^{2}$ values confirmed that this model was a good fit for the

276 experimental data. The $k$ values obtained for all the casein films are in the range observed for

277 other food materials (Quirijns et al., 2005). Negative values were obtained for $C_{G}$, which is a

278 physical impossibility. This has been attributed previously to insufficient data in the low $\mathrm{a}_{\mathrm{w}}$

279 region $\left(\mathrm{a}_{\mathrm{w}}<0.11\right)$ (Quirijns et al., 2005), which was also the case in this study. Nonetheless,

280 Quirijns et al., (2005) demonstrated that sorption isotherms are not sensitive to $C_{G}$ when based

281 on experimental data obtained at $\mathrm{a}_{\mathrm{w}}>0.11$. The $m_{0}$ values obtained for all film types were much

282 higher than the values generally obtained for food systems. This has been reported before for

283 foods containing plasticizers such as glycerol and sorbitol (Sherwin and Labuza, 2005).

284 Therefore, the GAB parameters shown in Table 1 can be used to accurately describe the sorption

285 isotherms in the $\mathrm{a}_{\mathrm{w}}$ range from 0.2 to 0.95 , but no further inferences can be made about the effect

286 of treatment conditions on the GAB parameters.

\subsection{Effect of PL on the Mechanical Properties of Casein Films}

The mechanical properties of the films obtained in this work were comparable to those of

290 other UV treated protein matrices, at similar $\mathrm{a}_{\mathrm{w}}$ values (Rhim et al., 1999; Gennadios et al.,

291 1998). Overall, the tensile strength (TS) of the casein films decreased significantly $(\mathrm{p}<0.05)$ as

$292 \mathrm{a}_{\mathrm{w}}$ increased. For all film types, TS decreased exponentially with $\mathrm{a}_{\mathrm{w}}$ (Fig. 6), which is a common

293 behavior for many food biopolymers. The numerical parameters of the exponential dependency

294 are shown in Table 2 . These changes in mechanical strength with $\mathrm{a}_{\mathrm{w}}$ were expected, since the 
295 presence of water molecules reduces the hydrogen bonding between the protein chains and 296 increases molecular spacing, which decreases mechanical strength (Cho and Rhee, 2002;

297 Hernandez-Izquierdo and Krochta, 2008). The resins had a plasticizing effect on the casein 298 matrix, as observed from the significantly lower TS values of the films with incorporated resins 299 compared to the casein film. The addition of the plasticizers changed the mechanical resistance 300 behavior of the films from brittle (high TS, low elongation) to ductile (lower TS, higher 301 elongation). This effect was particularly noticeable at $\mathrm{a}_{\mathrm{w}}<0.5$.

302 The film \% elongation (or ductility) was also significantly affected by $a_{w}(p<0.05)$,

303 although the effect of $a_{w}$ did depend on the type of film. The $\%$ elongation $-a_{w}$ correlation

304 followed an exponential relationship, although this was not statistically significant in most cases

305 (low $R^{2}$ values - not shown). As seen in Fig. 7, the \% elongation of the casein films increased 306 with $\mathrm{a}_{\mathrm{w}}$, while most of the films with incorporated resins became less elastic with increasing $\mathrm{a}_{\mathrm{w}}$.

307 This behavior is probably due to the fact that plasticized films were very weak, which caused 308 them to break easily as their $a_{w}$ increased. For the films not treated with PL, the elasticity of the 309 plasticized films, particularly those with PEG (200) DA, of $\mathrm{a}_{\mathrm{w}}<0.8$ was much higher (about $310120 \%$ elongation at $a_{w} \sim 0.15$ ) than for the casein films (about $20 \%$ elongation at $a_{w} \sim 0.15$ ). At $311 a_{w}>0.8$, all films had comparable levels of elasticity (50-60\% elongation) (Fig. 7).

312 For the casein films without resins, PL did not cause a statistically significant change in 313 tensile strength. The exception were the films treated with 15 pulses, for which the mechanical 314 strength decreased, due to the presence of cracks in their structure (Fig. 3C). PL-treated casein 315 films had significantly higher \% elongation as compared to the non-treated films $(\mathrm{p}<0.05)$. This 316 suggests some degree of cross-linking and the formation of a slightly more ductile network after 
317 PL treatment, since the formation of covalent bonds will allow the network to deform more

318 before reaching the breaking point.

319 The effect of PL was more noticeable for the films with incorporated resins. For the films

320 with PEG (400) DA, a significant increase in tensile strength after PL was observed in both

321 replicates $(\mathrm{p}<0.05)$ (Fig. 6, Table 2). However, the effect of PL on the \% elongation of these

322 films was only statistically significant in Replicate $1(\mathrm{p}<0.05)$. For the films with PEG (200)

323 DA, the increase in tensile strength after PL was statistically significant only in Replicate 2 ( $<<$

324 0.05), while the \% elongation decreased significantly after PL in both replicates $(\mathrm{p}<0.05)$.

325 These effects may be explained by the highly porous microstructure for the casein films with

326 PEG (200) DA (Fig. 3). Overall, despite the increase in mechanical strength of some of the PL

327 treated films, the tensile strength and elongation of all casein films produced were still lower

328 compared to those of synthetic films at equivalent humidity level (Gennadios et al., 1994).

329 Another observation that needs to be made is that crosslinking may in fact hinder the

330 biodegradability of the casein films. For example, Rimdusit et al. (2008) reported that in six

331 weeks, the carbon dioxide emission from cross-linked methyl cellulose (MC) films was reduced

332 around 80\% compared to pure MC. For casein films, both cross-linked and not cross-linked,

333 there is no information on the extent of biodegradability and this would have to be determined in

334 future work.

335

336 3.5. Effect of PL on Water Vapor Barrier Property of Casein Films

337 The water vapor permeability (WVP) values for all films are shown in Fig. 8. These

338 WVP values do not account for the direction of the water vapor diffusion process. 
PL treatment significantly changed the WVP of casein films $(\mathrm{p}<0.05)$. PL-treated

340 casein films had larger WVP values than untreated films, particularly at high \% RH gradients.

341 PL treatment did not significantly change WVP of casein films with PEG (200) DA or PEG

342 (400) DA. These results are rather contradictory when comparted to the changes in mechanical

343 properties reported above, and may be due to the increase affinity for water molecules of the PL

344 treated films.

345 The WVP values for the films with incorporated resins were generally higher than for the

346 casein films. For the highest \% RH gradient (88.41\%), the WVP of the casein films with added

347 resins were one to two orders of magnitude larger that for the casein films (Fig. 8). The increase

348 in WVP as a result of adding plasticizers is known, since plasticizers reduce intermolecular

349 forces along protein chains and increase the polymer free volume (Sothornvit and Krochta,

350 2000). The high WVP values observed at high \% RH gradient values for the casein films with

351 PEG (200) DA can also be explained by their porous structure. While for applications where

352 moisture transport needs to be prevented this is a disadvantage, such films may be useful in

353 situations where some degree of moisture transport is necessary, i.e. packaging of fresh fruits and

354 vegetables, where partial permeability to water vapors of the packaging material is required to 355 allow for respiration.

357 4. Conclusions

PL treatment seemed to induce some cross-linking in casein films, but excessive PL 359 doses also caused light-induced degradation and structural defects. The surface topography of 360 casein films also became smoother after PL treatment. Mechanical strength and elongation of 361 casein films with added PEG (400) DA, a UV-curable resin, were increased by PL treatment, 
362 although no improvement of their water vapor permeability was observed. The incorporation of

363 PEG (200) DA resulted in highly porous film microstructures, which may be suitable for specific

364 applications that require water vapor transport, such as packaging of fresh produce. Overall, PL

365 has some potential for inducing changes in the functional and structural properties of casein

366 films, although the properties in the films obtained in this study were still inferior to synthetic

367 polymeric films.

\section{Acknowledgements}

370 This research was supported by the Cornell University Agricultural Experiment Station

371 federal formula funds received from the Cooperative State Research, Education and Extension

372 Service, U.S. Department of Agriculture. Any opinions, findings, conclusions, or

373 recommendations expressed in this publication are those of the authors and do not necessarily

374 reflect the view of the U.S. Department of Agriculture.

375

376 References

377 ASTM. (2003). Designation D 882-02: Standard test method for tensile properties of thin plastic 378 sheeting. In Annual Book of ASTM Standards (pp.161-169). American Society for 379 Testing and Materials, Philadelphia, PA.

380 Avena-Bustillos, R.J. and Krochta, J.M. (1993). Water vapor permeability of caseinate-based 381 edible films as affected by $\mathrm{pH}$, calcium crosslinking and lipid content. Journal of Food $382 \quad$ Science, 58(4), 904-907. 
Baroli, B. (2006). Review: Photopolymerization of biomaterials: issues and potentialities in drug delivery, tissue engineering, and cell encapsulation applications. Journal of Chemical Technology and Biotechnolgy, 81, 491-499.

Cheigh, C.I., Park M.H., Chung M.S., Shin J.K., and Young-Seo Park. 2012. Comparison of intense PL and UV (UVC) induced cell damage in Listeria monocytogenes and Escherichia coli O157:H7. Food Control 25: 654-659

Cho, S.Y. and Rhee, C. (2002). Sorption characteristics of soy protein films and their relation to mechanical properties. Lebensmittel-Wissenschaft \& -Technologie, 35, 151-157.

Choi, D., Lee, W., Lee, Y., Kim, D.N., Park, J., and Koh, W.G. (2008). Fabrication of macroporous hydrogel membranes using photolithography for enzyme immobilization. Journal of Chemical Technology \& Biotechnology, 83(3), 252-259.1

Dunn, J., Clark, R.W., Asmus, J.F., Pearlman, J.S., Boyer, K., Pairchud, F., and Hofmann, G. (1991). Methods for preservation of foodstuffs. Maxwell Laboratories, Inc. US Patent $5,034,235$.

Fabra, M.J., Talens, P., Chiralt, A. (2008). Effect of alginate and $\lambda$-carrageenan on tensile properties and water vapour permeability of sodium caseinate-lipid based films. Carbohydrate Polymers, 74(3), 419-426.

Fabra, M.J., Talens, P., Chiralt, A. (2009). Microstructure and optical properties of sodium caseinate films containing oleic acid-beeswax mictures. Food Hydrocoloids, 23(3), 676683.

Foster, K.D., Bronlund, J.E., and Paterson, A.H.J. (2005). The prediction of moisture sorption isotherms for dairy powders. International Dairy Journal, 15, 411-418. 
Gennadios, A., McHugh, T.H., Weller, C.L., and Krochta, J.M. (1994). Edible coatings and films based on proteins. In Krochta, J.M., Baldwin, E.A., and Nisperos-Carriedo, M. (eds.), Edible Films and Coatings to Improve Food Quality (pp. 201-277). Technomic Publishing Company, Inc., Lancaster, PA.

Gennadios, A., Rhim, J.W., Handa, A., Weller, C.L., and Hanna, M.A. (1998). Ultraviolet radiation affects physical and molecular properties of soy protein films. Journal of Food Science, 63(2), 225-228.

Goddard, J.M. and Hotchkiss, J.H. (2007). Polymer surface modification for the attachment of bioactive compounds. Progress in Polymer Science, 32, 698-725.

Hernandez-Izquierdo, V.M. and Krochta, J.M. (2008). Thermoplastic processing of proteins for film formation - a review. Journal of Food Science, 0(00), R1-R10.

Ifkovits, J.L. and Burdick, J.A. (2007). Photopolymerizable and degradable biomaterials for tissue engineering applications. Tissue Engineering, 13, 2369-2385.

Iglesias, H.A. and Chirife, J. (1982). Handbook of food isotherms: water sorption parameters for food and food components. Food science and technology - A series of monographs. Academic Press, New York.

Jangchud, A. and Chinnan, M.S. (1999). Properties of peanut protein film: sorption isotherm and plasticizer effect. Lebensmittel-Wissenschaft und-Technologie, 32, 89-94.

Kester, J.J. and Fennema, O. 1989. An edible film of lipids and cellulose ethers: Performance in a model frozen-food system. Journal of Food Science, 54(6): 1390-1392.

Krochta, J.M. (1992). Control of mass transfer in foods with edible-coatings and films. In Singh, R.P. and Wirakartakusumah, M.A. (eds.), Advances in Food Engineering (pp. 517-538). CRC Press, Inc., Boca Raton, FL. 
428 Krishnamurthy, K., Tewari, J. C., Irudayaraj, J., and Demirci, A. 2010. Microscopic and spectroscopic evaluation of inactivation of Staphylococcus aureus by pulsed UV light and infrared heating. Food and Bioprocess Technology, 3: 93-104.

McHugh, T.H. and Krochta, J.M. (1994). Permeability properties of edible films. In Krochta, J.M., Baldwin, E.A., and Nisperos-Carriedo, M. (eds.), Edible Films and Coatings to Improve Food Quality (pp. 139-187). Technomic Publishing Company, Inc., Lancaster, PA.

Pereda, M. Aranguren, M.I. Marcovich, N.E. (2008). Characterization of chitosan/caseinate films. Journal of Applied Polymer Science, 107(2), 1080-1090.

Quirijns, E.J., van Boxtel, A.J.B., van Loon, W.K.P., and van Straten, G. (2005). An improved experimental and regression methodology for sorption isotherms. Journal of the Science

443 Rimdusit S., Jingjid S., Damrongsakkul S., Tiptipakorn S., and Takeichi T. 2008. of Food and Agriculture, 85, 175-185.

Rhim, J.W., Gennadios, A., Fu, D., Weller, C.L., and Hanna, M.A. (1999). Properties of ultraviolet irradiated protein films. Lebensmittel-Wissenschaft \& -Technologie, 32, 129-

Scherzer, T., Knolle, W., Naumov, S., and Prager, L. (2005). Investigations on the photoinitiator-free photopolymerization of acrylates by vibrational spectroscopic methods. Macromolecular Symposia, (230), 173-182. 
Sherwin, C.P. and Labuza, T.P. (2003). Role of moisture in Maillard browning reaction rate in intermediate moisture foods: Comparing solvent phase and matrix properties. Journal of Food Science, 68(2), 588-594.

Sothornvit R. and Krochta, J.M. (2000). Water vapor permeability and solubility of films from hydrolyzed whey protein. Journal of Food Science, 65(4), 700-703.

Sohail, S.S., Wang, B., Biswas, M.A.S., and Oh, J.H. (2006). Physical, morphological, and barrier properties of edible casein films with wax applications. Journal of Food Science, 71(4): 255-259.

Uesugi A. and Moraru C.I. (2009). Reduction of Listeria on ready-to-eat sausages after exposure to a combination of Pulsed Light and nisin. Journal of Food Protection, 72(2), 347-353.

Uesugi, A., Woodling S.E. and Moraru C.I. (2007). Inactivation kinetics and factors of variability in the Pulsed Light treatment of Listeria innocua cells. Journal of Food Protection, 70(11), 2518-2525.

Vaz, C.M., De Graaf, L.A., Reis, R.L., and Cunha, A.M. (2003) Effect of crosslinking, thermal treatment and UV irradiation on the mechanical properties and in vitro degradation behavior of several natural proteins aimed to be used in the biomedical field. Journal of Material Science: Materials in Medicine, 14: 789-796.

Wihodo M. and Moraru C.I. (2013). Physical and chemical methods used to enhance the structure and mechanical properties of protein films. A review. Journal of Food Engineering 114(3): 292-302

Woodling S.E. and Moraru C.I. (2007). Effect of spectral range in surface inactivation of Listeria innocua using broad spectrum Pulsed Light. Journal of Food Protection, 70(4), 906-916. 
471 Zubkov, T., Stahl, D., Thompson, T.L., Panayotov, D., Diwald, O., and Yates, J.T. Jr. (2005). Ultraviolet light-induced hydrophilicity effect on TiO2(110)(1 x 1). Dominant role of the

473 photooxidation of adsorbed hydrocarbons causing wetting by water droplets. $J$ Phys

$474 \quad$ Chem B. 109(32):15454-62.

475 
477 Table 1. GAB model constants and goodness of the fit $\left(R^{2}\right)$ for all film types at different PL

478 treatment levels

\begin{tabular}{|c|c|c|c|c|c|}
\hline Film type & PL Treatment & $C_{G}{ }^{\mathrm{a}}$ & $k^{\mathbf{a}}$ & $m_{0}^{b}$ & $R^{2}$ \\
\hline Casein & $\begin{array}{l}0 \text { pulses (Control) } \\
9 \text { pulses }\left(14.1 \mathrm{~J} / \mathrm{cm}^{2}\right) \\
12 \text { pulses }\left(18.8 \mathrm{~J} / \mathrm{cm}^{2}\right) \\
15 \text { pulses }\left(23.5 \mathrm{~J} / \mathrm{cm}^{2}\right)\end{array}$ & $\begin{array}{l}-79.45 \\
-41.44 \\
-23.28 \\
-17.17\end{array}$ & $\begin{array}{l}0.91 \\
0.93 \\
0.93 \\
0.95\end{array}$ & $\begin{array}{l}0.18 \\
0.17 \\
0.16 \\
0.14\end{array}$ & $\begin{array}{l}0.86 \\
0.91 \\
0.91 \\
0.97\end{array}$ \\
\hline Casein + PEG (200) DA & $\begin{array}{l}0 \text { pulses (Control) } \\
9 \text { pulses }\left(14.1 \mathrm{~J} / \mathrm{cm}^{2}\right) \\
12 \text { pulses }\left(18.8 \mathrm{~J} / \mathrm{cm}^{2}\right) \\
15 \text { pulses }\left(23.5 \mathrm{~J} / \mathrm{cm}^{2}\right)\end{array}$ & $\begin{array}{l}-17.16 \\
-28.22 \\
-27.52 \\
-25.92\end{array}$ & $\begin{array}{l}0.88 \\
0.88 \\
0.88 \\
0.86\end{array}$ & $\begin{array}{l}0.26 \\
0.24 \\
0.25 \\
0.24\end{array}$ & $\begin{array}{l}0.90 \\
0.91 \\
0.94 \\
0.91\end{array}$ \\
\hline Casein + PEG (400) DA & $\begin{array}{l}0 \text { pulses (Control) } \\
9 \text { pulses }\left(14.1 \mathrm{~J} / \mathrm{cm}^{2}\right) \\
12 \text { pulses }\left(18.8 \mathrm{~J} / \mathrm{cm}^{2}\right) \\
15 \text { pulses }\left(23.5 \mathrm{~J} / \mathrm{cm}^{2}\right)\end{array}$ & $\begin{array}{l}-18.61 \\
-17.71 \\
-14.57 \\
-12.58\end{array}$ & $\begin{array}{l}0.92 \\
0.90 \\
0.92 \\
0.91\end{array}$ & $\begin{array}{l}0.19 \\
0.18 \\
0.17 \\
0.16\end{array}$ & $\begin{array}{l}0.91 \\
0.94 \\
0.86 \\
0.86\end{array}$ \\
\hline \multicolumn{6}{|l|}{${ }^{\mathrm{a}}$ GAB constants } \\
\hline${ }^{\mathrm{b}}$ Monolayer moisture con & nt (kg/kg d.b.) & & & & \\
\hline
\end{tabular}


482 Table 2. Parameters of the Tensile strength (TS) - water activity $\left(a_{w}\right)$ exponential relationship

$483\left(T S=a e^{b a_{w}}\right)$ and goodness of the fit $\left(R^{2}\right)$ for all film types

\begin{tabular}{|l|c|c|c|c|c|c|c|c|c|}
\hline \multicolumn{1}{|c|}{ Film type } & \multicolumn{3}{c|}{ Casein } & \multicolumn{3}{c|}{ Casein + PEG(200)DA } & \multicolumn{2}{c|}{ Casein + PEG(400)DA } \\
Treatment & $\boldsymbol{a}$ & $\boldsymbol{b}$ & $\boldsymbol{R}^{2}$ & $\boldsymbol{a}$ & $\boldsymbol{b}$ & $\boldsymbol{R}^{2}$ & $\boldsymbol{a}$ & $\boldsymbol{b}$ & $\boldsymbol{R}^{2}$ \\
0 (Control) & 25.14 & -4.55 & 0.85 & 11.28 & -3.37 & 0.89 & 5.49 & -2.58 & 0.90 \\
9 pulses & 22.65 & -4.36 & 0.91 & 8.18 & -2.73 & 0.94 & 7.70 & -2.67 & 0.94 \\
12 pulses & 25.14 & -4.39 & 0.92 & 9.26 & -3.11 & 0.92 & 7.81 & -2.59 & 0.93 \\
15 pulses & 19.35 & -3.84 & 0.88 & 9.08 & -2.93 & 0.92 & 8.19 & -2.66 & 0.86 \\
\hline
\end{tabular}



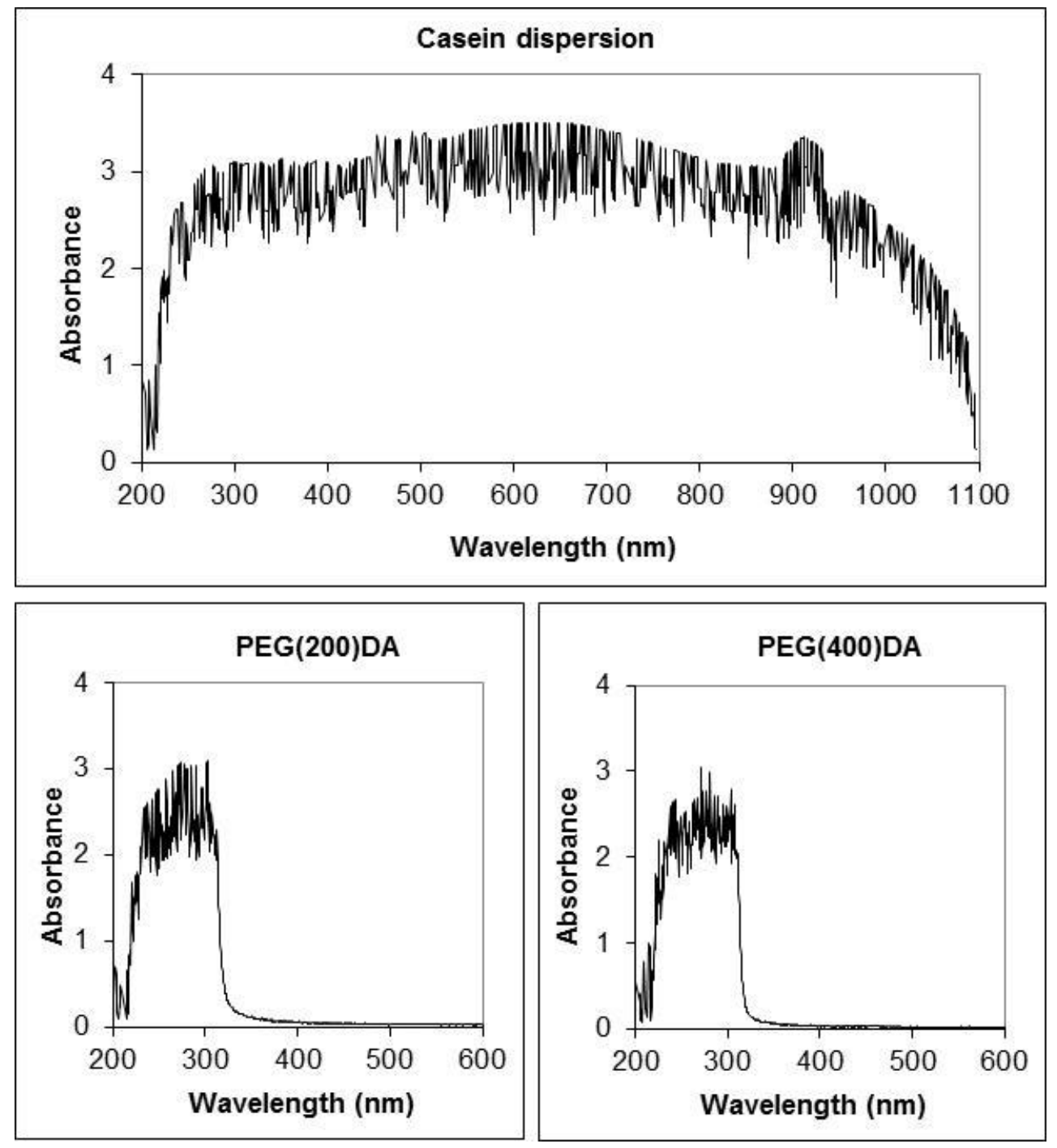

487 Figure 1. Light absorption spectra for casein dispersion and the liquid photoinitiators (PEG-200 488 and PEG-400) 


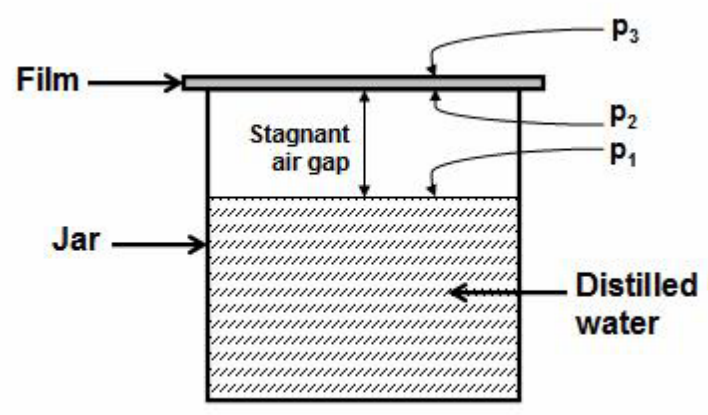

490

491 Figure 2. Schematic diagram of the water vapor permeability measurement rig, indicating the

492 locations of water vapor pressure and the air gap (headspace) height

493 


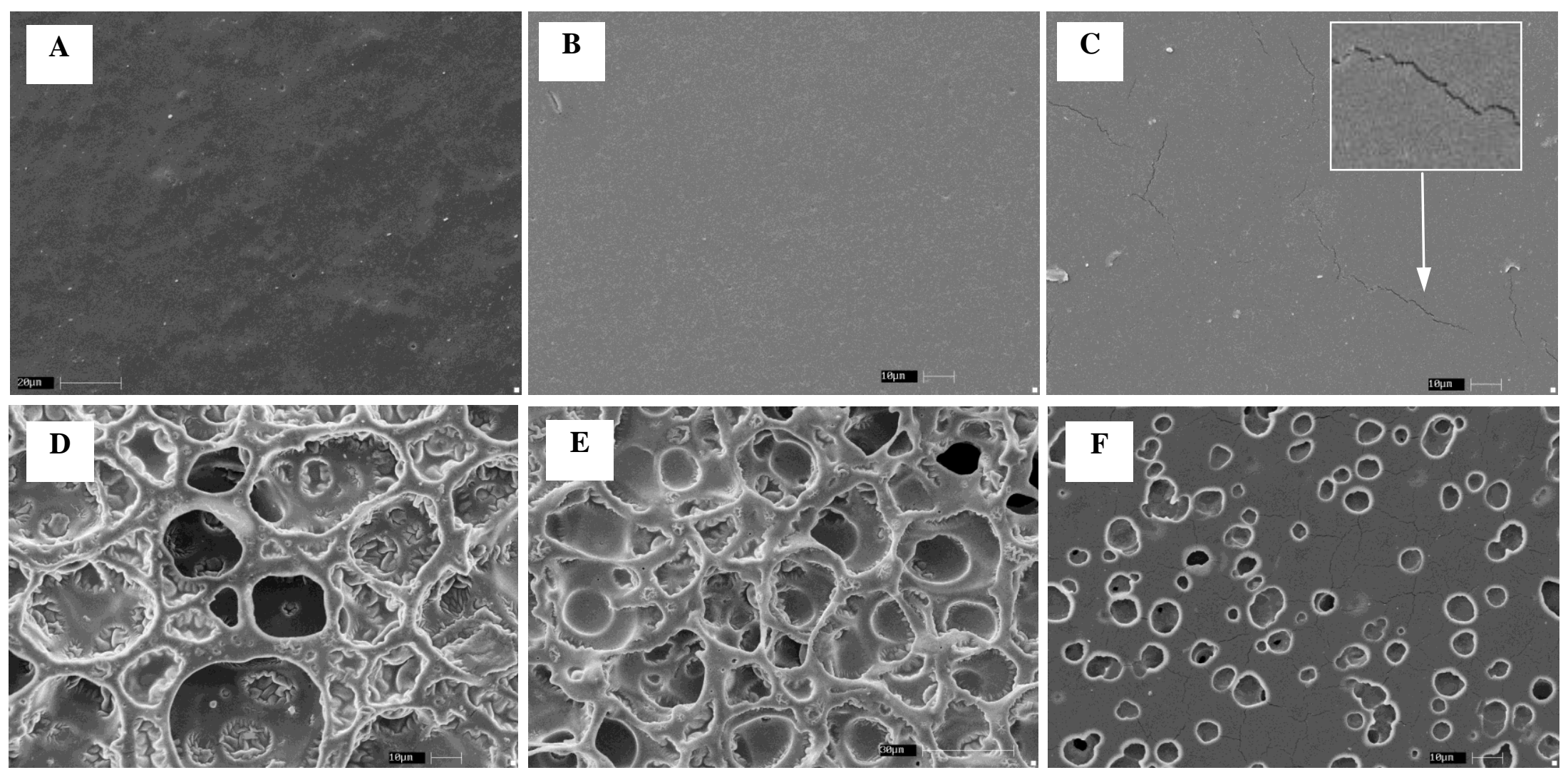

495 Figure 3. SEM images (1500 X) of casein films (A, B, C) and casein films with PEG (200) diacrylate (D, E, F) before and after PL

496 treatment: $[\mathrm{A}, \mathrm{D}]-0$ pulses; $[\mathrm{B}, \mathrm{E}]-12$ pulses; and $[\mathrm{C}, \mathrm{F}]-15$ pulses. Photos for films treated with 9 pulses of light look similar to

497 those treated with 12 pulses and are not shown. 


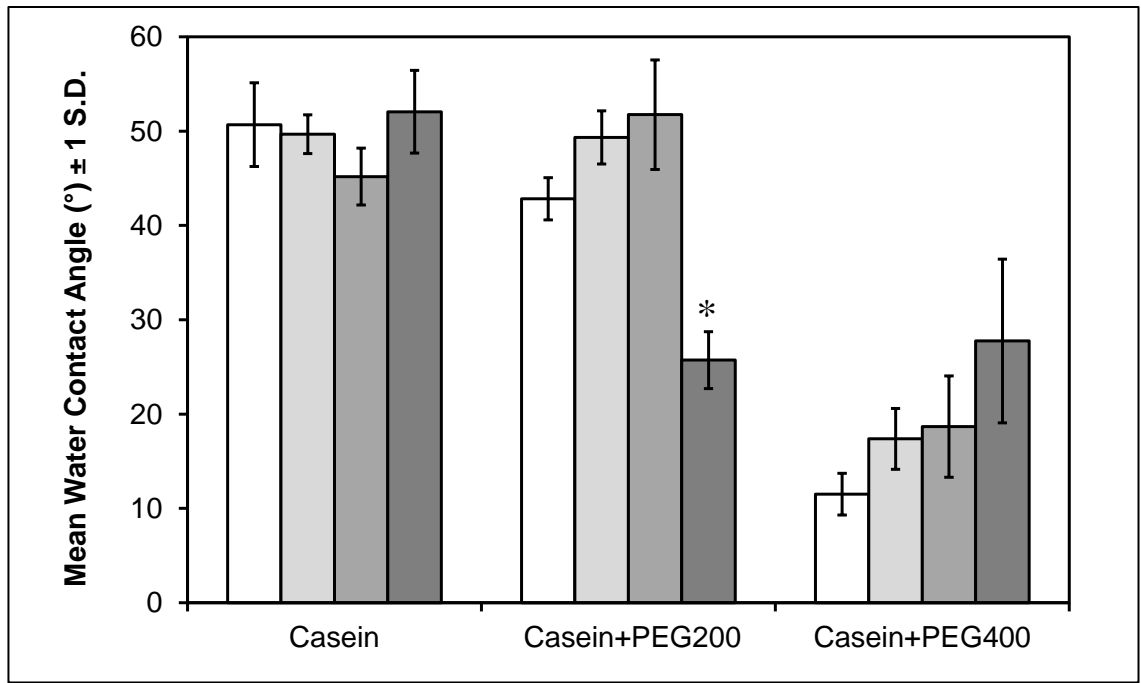

499 Figure 4. Water contact angle of casein films, casein films with PEG (200) DA, and casein

500 films with PEG (400) DA, after different PL treatments: untreated ( $\square$ ); treated with 9 pulses ( $\square$ );

501 treated with 12 pulses ( $\square$ ); and treated with 15 pulses ( $\square$ ). Asterisks indicate significant

502 differences within a composition group, at $\alpha=0.05$. 

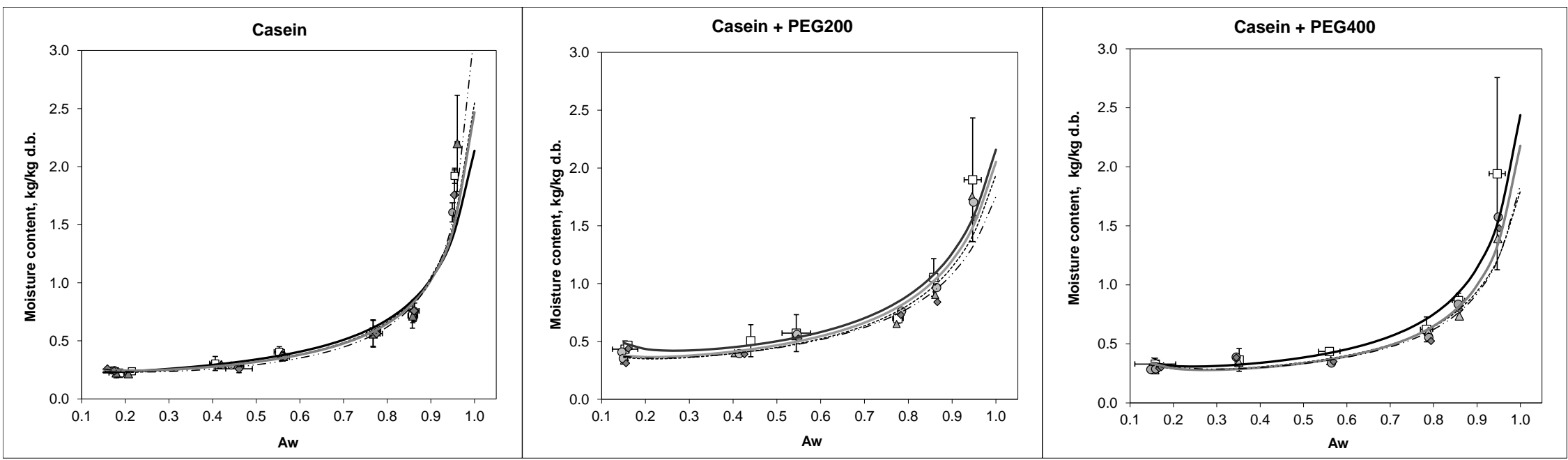

504 Figure 5. Effect of PL treatment on the moisture sorption isotherms of the three types of films (casein, casein with PEG (200) DA

506 pulses $(\diamond)$; and the lines GAB predictions: 0 pulses $(-) ; 9$ pulses $(\cdots \cdot \cdots) ; 12$ pulses $(-)$; and 15 pulses $\left({ }^{-*-*-)}\right.$ 

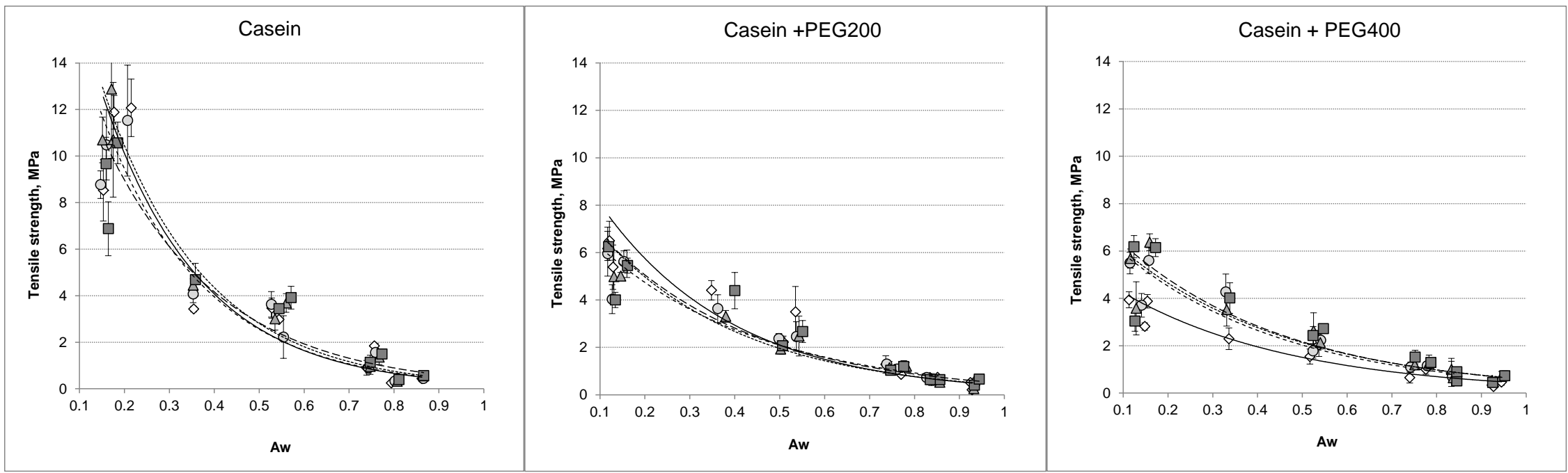

509 Figure 6. Tensile strength of casein films after PL treatment with 0, 9, 12, and 15 pulses and conditioning at different \% RH

510 conditions (combined data from Replicate 1 and Replicate 2). Data points represent average values and error bars indicate 1 standard

511 deviation for measurements within a replicate. The symbols indicate measured vales: 0 pulses $(\diamond)$; 9 pulses $(\odot)$; 12 pulses $(\Delta)$; and

51215 pulses ( $\square)$; and the lines indicate regression lines: 0 pulses (-); 9 pulses (- - ); 12 pulses ( ( .....); and 15 pulses (- - $)$ ). 

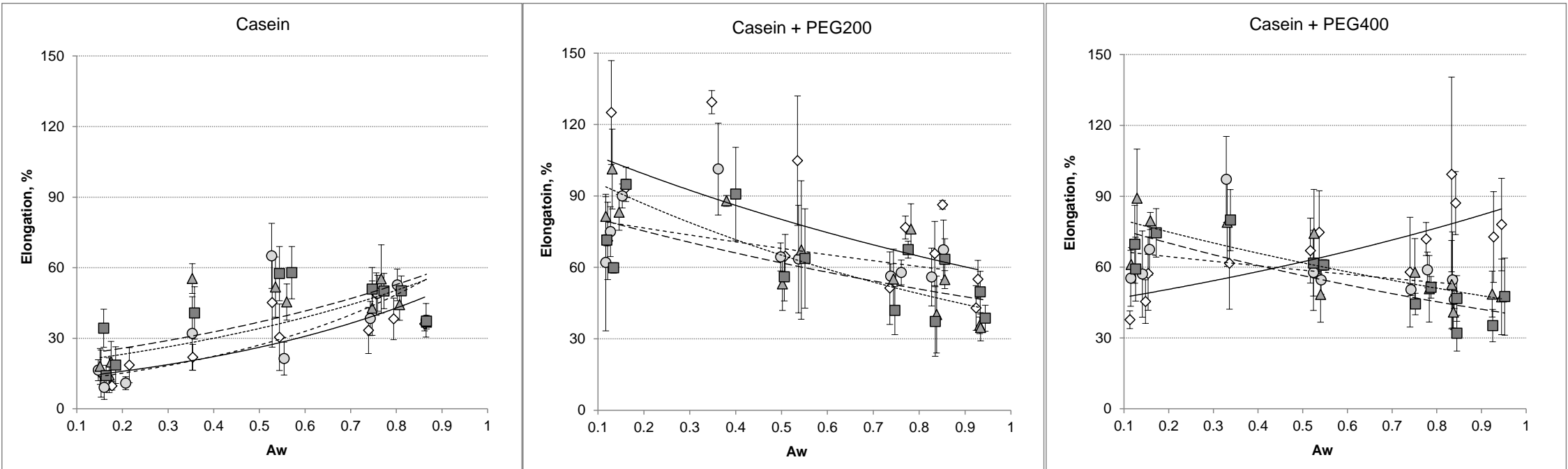

515 Figure 7. \% Elongation of casein films after PL treatment with $0,9,12$, and 15 pulses and conditioning at different \% RH conditions

516 (combined data from Replicate 1 and Replicate 2). Data points represent average values and error bars indicate 1 standard deviation

517 for measurements within a replicate. The symbols indicate measured vales: 0 pulses $(\diamond)$; 9 pulses $(\diamond) ; 12$ pulses $(\Delta)$; and 15 pulses

518 ( $\square)$; and the lines indicate exponential trendlines: 0 pulses (-); 9 pulses (- - ); 12 pulses (….); and 15 pulses (- - $)$. 

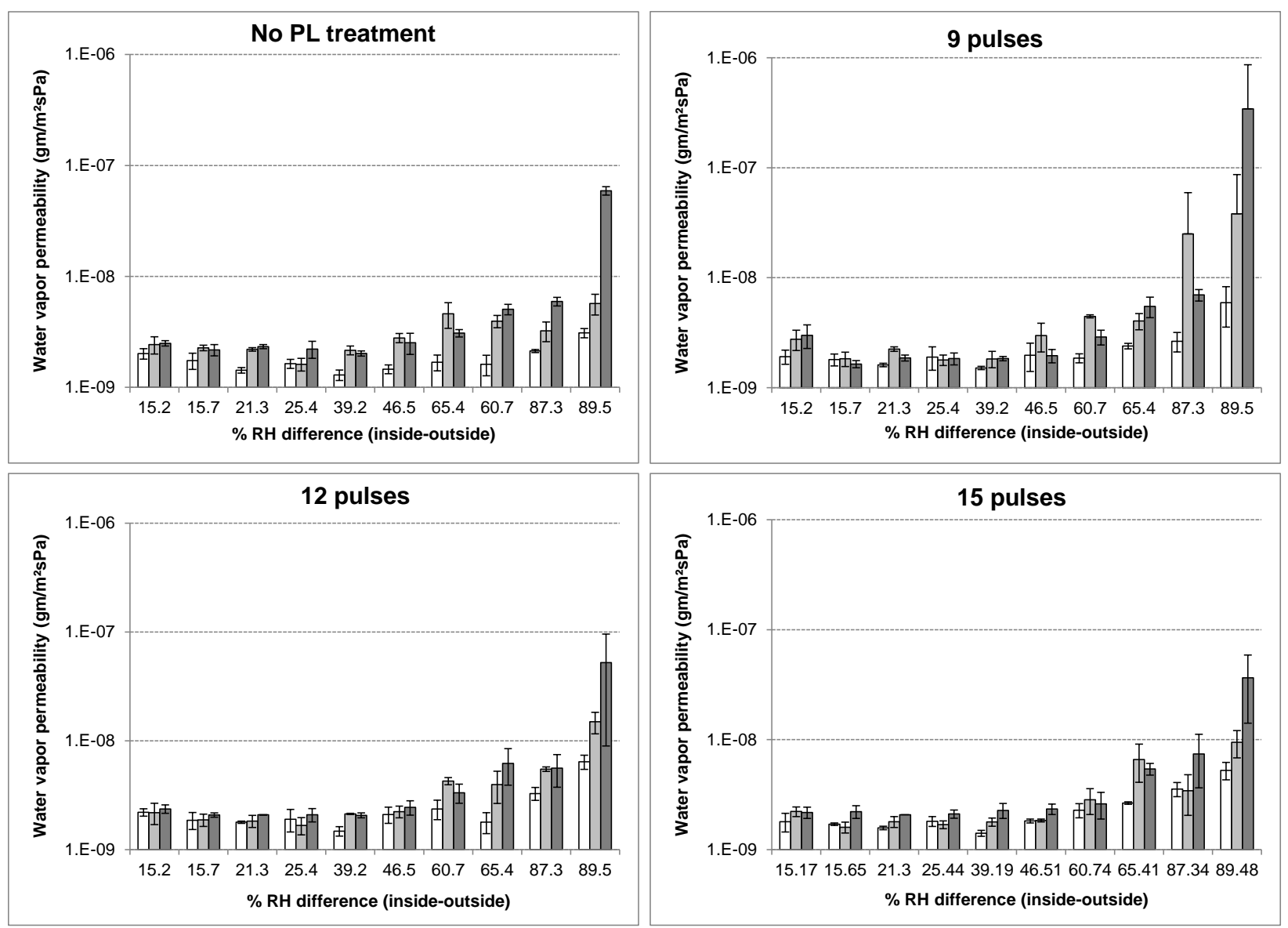

520 Figure 8. Water vapor permeability of casein films ( $\square$ ), casein with PEG (200) DA films ( $\square$ )

521 and casein with PEG (400) DA films ( $\square$ ) after PL treatment with 0, 9, 12, and 15 pulses and

522 conditioning at different \% RH (combined data from Replicate 1 and Replicate 2). 